\title{
Household preparedness motivation in lahar hazard zones: assessing the adoption of preparedness behaviors among laypeople and response professionals in communities downstream from Mount Baker and Glacier Peak (USA) volcanoes
}

\author{
Kimberley A. Corwin ${ }^{1 *}$, Brittany D. Brand ${ }^{1}$, Monica L. Hubbard² and David M. Johnston ${ }^{3}$
}

\begin{abstract}
As the number of people living at risk from volcanic hazards in the U.S. Pacific Northwest grows, more detailed studies of household preparedness in at-risk communities are needed to develop effective mitigation, response, and recovery plans. This study examines two aspects of preparedness behavior motivation in the Skagit Valley (WA), which is at risk from Mount Baker and Glacier Peak lahars. First, we examine the influence of perceived responseefficacy, protective response costs, self-efficacy, and ascription of responsibility on preparedness. Results indicate few respondents believe high perceived protective response costs, low perceived response-efficacy, or low perceived protection responsibility prevent them from adopting frequently recommended preparedness behaviors. Correlations with preparedness suggest perceived self-efficacy and ascription of responsibility play a more dominant role in determining preparedness behaviors, albeit a less readily recognized role. Second, we investigate how participation in hazard management at a professional level (e.g., working as a first responder or leader within the local city government, hospitals, school districts, Red Cross, or utilities, transportation, or water companies) influences knowledge, risk perception, and household preparedness. Results show that professional participation minimally influences household preparedness, but successfully improves perceived self-efficacy, confidence in officials, and information seeking behavior. Given these results, we argue (1) for inclusion of ascription of responsibility variables in studies of preparedness behavior motivation and (2) that specific types of participation in response-related activities (e.g., public, professional, specific training programs) may affect household preparedness differently, whereas self-efficacy and confidence in officials may improve regardless of participation type because of increased interaction with emergency officials.
\end{abstract}

Keywords: Preparedness, Behavior motivation, Volcanic lahar hazards, Risk perception, Disaster Risk Management, Protection Motivation Theory, Values-Beliefs-Norms Theory, Protective Action Decision Model, Expert and lay, Participation

\footnotetext{
* Correspondence: kimberleycorwin@u.boisestate.edu

${ }^{1}$ Department of Geosciences, Boise State University, Boise, ID, USA

Full list of author information is available at the end of the article
} 


\section{Introduction}

As populations around the world encroach upon the flanks of nearby volcanoes, an increasing number of people find themselves living at risk from volcanic hazards. How these individuals respond to the threats posed by volcanic hazards influences the effectiveness of official hazard mitigation, response, and recovery efforts. Ideally, those who are aware of the hazards and concerned should feel motivated to become better prepared; however, research repeatedly shows that an accurate risk perception often fails to generate adequate preparedness (Sims and Baumann 1983 and references therein; Paton et al. 2008; Wachinger et al. 2013 and references therein; Corwin 2016). The existence of such a disconnect raises two questions: what factors, aside from awareness and risk perception, influence household preparedness actions; and what can be done to improve community preparedness levels? To address these questions, this study explores the barriers that people in the Skagit Valley of Washington face when deciding whether or not to prepare for lahars as well as the impact of participation in hazard management on household preparedness behaviors.

To examine potential barriers to household preparedness, we explore the influence of factors outlined in three prominent behavior motivation theories, the Protection Motivation Theory (PMT; Rogers 1983; Rogers and Prentice-Dunn 1997; Grothmann and Reusswig 2006), the Protective Action Decision Model (PADM; Lindell and Perry 1992; Lindell and Perry 2012), and the Values-Beliefs-Norms Theory (VBN; Stern et al. 1999; Stern 2000). The first two are frequently applied to natural hazard preparedness while the third focuses primarily on explaining support for environmental movements.

\section{Theoretical framework and research questions}

In PMT, an individual's threat appraisal (i.e., risk perception; Grothmann and Reusswig 2006) and coping appraisal determine the motivation and direction of protective actions. Threat appraisal incorporates perceived probability of exposure, perceived severity of damage, and fear of the hazard. Coping appraisal incorporates perceived protective response efficacy (i.e., judgments of the effectiveness of preparedness actions for addressing the threat), perceived self-efficacy (i.e., belief in one's ability to act), and perceived protective response costs (i.e., perceptions of the cost associated with protective actions in terms of money, time, knowledge, and effort). Grothmann and Reusswig (2006) demonstrate that one's coping appraisal influences preparedness behaviors to a far greater degree than one's threat appraisal. However, Grothmann and Reusswig do not distinguish between the role of each of the three components that make up the coping appraisal.
More detailed investigations of some of these individual components are found in studies applying PADM (e.g., Houts et al. 1984; Lindell and Perry 1992, 2012; Lindell and Whitney 2000; Lindell and Prater 2002; Terpstra and Lindell 2012). PADM explains that preparedness intentions and behaviors depend on hazardrelated and resource-related attributes. Hazard-related attributes represent a more detailed measure of perceived response-efficacy that includes efficacy for protecting people, efficacy for protecting property, and utility of the adjustment for other purposes. Responserelated attributes measure characteristics of protective actions rather than characteristics of the people responding. PADM's response-related attributes focus on the perceived amount of money, time, effort, knowledge, and skills required for implementing a protective action. The perceptions of money and time expenditures are similar to PMT's concept of perceived protective response costs. Yet, differences exist in how PADM and PMT are conceptualized and operationalized in different studies, and PADM lacks the perceived self-efficacy concept found in PMT.

In VBN theory, Stern and colleagues (Stern et al.1999; Stern 2000) propose that support for environmental movements emanates from one's personal values, a worldview consistent with the New Ecological Paradigm (i.e., an ecological worldview centered on the relationship between humans and the natural world), an awareness of consequences, an ascription of responsibility to self, and personal norms (Stern et al. 1999; Stern 2000; Slimak and Dietz 2006). In short, individuals hold certain values, beliefs, and worldviews and recognize when they are threatened. Aware of negative consequences and believing themselves personally responsible for protecting their values, individuals feel obliged to take action.

The relationship between ascription of responsibility and behavior motivation was also investigated in the context of natural hazard preparedness by Lindell and Whitney (2000) and Arlikatti et al. (2007). Both studies examine the level of protective responsibility that respondents attribute to various stakeholders (e.g., federal, state, and local government officials, the media, employers, university officials, friends/peers, family, and self) with regard to seismic hazards. In both studies, respondents rate themselves as most responsible for their personal safety, with government officials considered the next most responsible, and the media, one's peers, and one's friends rated as least responsible. Lindell and Whitney further note that positive correlations exist between personal responsibility and preparedness intentions and actions. Taking into account these findings, Lindell and Perry's (2012) theory modification incorporates attribution of protective responsibility (i.e., 
ascription of responsibility) as part of PADM's perceptions of social stakeholders. PMT, however, currently lacks a concept equivalent to ascription of responsibility.

To improve the adoption of preparedness behaviors, previous studies (Barberi et al. 2008; Paton et al. 2008; Wachinger et al. 2013) have advocated for increasing public participation in the hazard management process. By more frequently interacting with emergency officials, the public improves their knowledge of local hazards and how to prepare. They gain an appreciation for the role of emergency agencies during hazard responses, learning what external support to reasonably expect and when to rely on their own agency. People reclaim responsibility for their personal safety rather than placing this responsibility in the hands of emergency services. This recognition of personal responsibility, coupled with elevated self-efficacy, helps motivate preparedness actions (Paton 2003; Wachinger et al. 2013). Interactions with officials also strengthen individual and community trust in officials, which, combined with an understanding of the role of emergency agencies, fosters a setting in which individuals heed emergency information and warnings (Wachinger et al. 2013). As the public feels increasingly knowledgeable, empowered, and trusting, they become more motivated to adopt preparedness actions.

Past studies (Barberi et al. 2008; Paton et al. 2008; Wachinger et al. 2013) focus almost exclusively on the impact of increased participation by members of the general public. However, participation takes many forms, from public responder programs (e.g., CERT) to public engagement in meetings and discussions with emergency officials. Additionally, the public are not the only community members that participate in hazard management and influence whole community preparedness. Response professionals (i.e., individuals who work as first responders or in a leadership role within the local city government, hospitals, school districts, Red Cross, or utilities, transportation, or water companies) actively participate in hazard response planning and implementation. Thus, one might expect that the demonstrated positive effects experienced by members of the public who participate in hazard management would be equally or more considerably felt by response professionals. However, few studies have examined the influence of professional participation on preparedness behaviors in a similar fashion to studies of public participation.

Recent research on response professionals deals largely with organizational preparedness and professional competencies (i.e., whether or not an individual has the knowledge, skills, and abilities required to perform their professional response duties) with a focus on health care professionals (Parker et al. 2005; Slepski 2007). Those few studies that examine household preparedness levels among public health employees (Blessman et al. 2007;
Rebmann et al. 2013) and first responders (Federal Emergency Management Agency n.d.) consistently indicate that household preparedness among respondents remains low. Yet, these studies fail to examine public household preparedness levels for comparison. As such, the comparative influence of hazard management participation at a professional level on household preparedness, knowledge, self-efficacy, personal responsibility beliefs, and trust remains unclear.

In summary, this study focuses on determining how people living or working in the Skagit Valley of Washington frame and respond to risks from volcanic lahars through a place-based knowledge, risk perception, and preparedness survey. Specifically, we examine the following research questions:

1. How do respondents rate the relative influence of perceived response-efficacy, protective response costs, self-efficacy, and ascription of responsibility on their adoption of preparedness behaviors, and how do additional measures of perceived self-efficacy and ascription of responsibility relate to actual household preparedness levels?

2. Given the positive influence that public participation in risk management has on public preparedness, does participation in hazard response planning and implementation at a professional level also translate into improved household preparedness, volcanic hazard knowledge, confidence in officials, perceived self-efficacy, and ascription of responsibility?

\section{Hazard and site description}

This study focuses on volcanic lahar hazards from Mount Baker and Glacier Peak in the Skagit Valley of northwestern Washington state. Commonly referred to as volcanic mudflows (Waitt et al. 1995), lahars are mixtures of water and debris that originate on a volcano and flow downslope under the influence of gravity (Vallance 2000; Volcano Hazards Program U.S. Geological Survey 2016). Lahars can be triggered during volcanic eruptions when hot, freshly erupted material melts and mixes with glacial water or a portion of the volcanic edifice collapses. Lahars can also occur post-eruption or form independent of an eruption (Rodolfo 2000; Vallance 2000). These secondary lahars typically result from nonvolcanic earthquakes that trigger edifice collapses or intense rainfall and lake breakouts that remobilize loose pyroclastic deposits.

After initiation, lahars move downslope, typically along river drainages, and bulk up by eroding and incorporating surrounding material (Rodolfo 2000; Vallance 2000). Dense, cohesive lahars with high carrying capacities entrain large boulders and debris (Pierson and Scott 1985; Vallance 2000). More dilute, non-cohesive lahars allow 
large debris to settle out while smaller, more buoyant particles remain entrained (Pierson and Scott 1985; Vallance 2000). Both cohesive and non-cohesive lahars can cause extensive damage to the built environment as boulders destroy structures and mud floods into and buries communities. Their speed, which ranges from a few meters per second to several tens of meters per second (Volcano Hazards Program U.S. Geological Survey 2016), exacerbates the potential for damage.

The Skagit Valley was selected for this study because populated communities intersect substantially with lahar hazard zones from two volcanoes (Fig. 1), both of which exhibit conditions and eruptive histories that favor lahar generation. Mount Baker is the second most glaciated volcano in the Cascades after Mount Rainier (Gardner et al. 1995), and Glacier Peak is the second most explosive after Mount St. Helens (Waitt et al. 1995). Extensive glaciation and available pyroclastic material leaves each prone to lahars. In fact, geologic assessments indicate multiple episodes of eruptive activity and lahar generation at both volcanoes during the past 14,000 years (Hyde and Crandell 1978; Beget 1982, 1983; Gardner et al. 1995; Waitt et al. 1995; Diefenbach et al. 2015). The largest of these episodes included lahars that traveled over $100 \mathrm{~km}$ downstream to Puget Sound and into now populated areas (Hyde and Crandell 1978; Beget 1982; Gardner et al. 1995; Dragovich and McKay 2000; Kovanen et al. 2001).

Seven towns (Mount Vernon, Sedro-Woolley, Burlington, La Conner, Concrete, Hamilton, and Lyman) lie either partially or fully within the lahar zones for both Mount Baker and Glacier Peak (Fig. 1). Risk mapping using

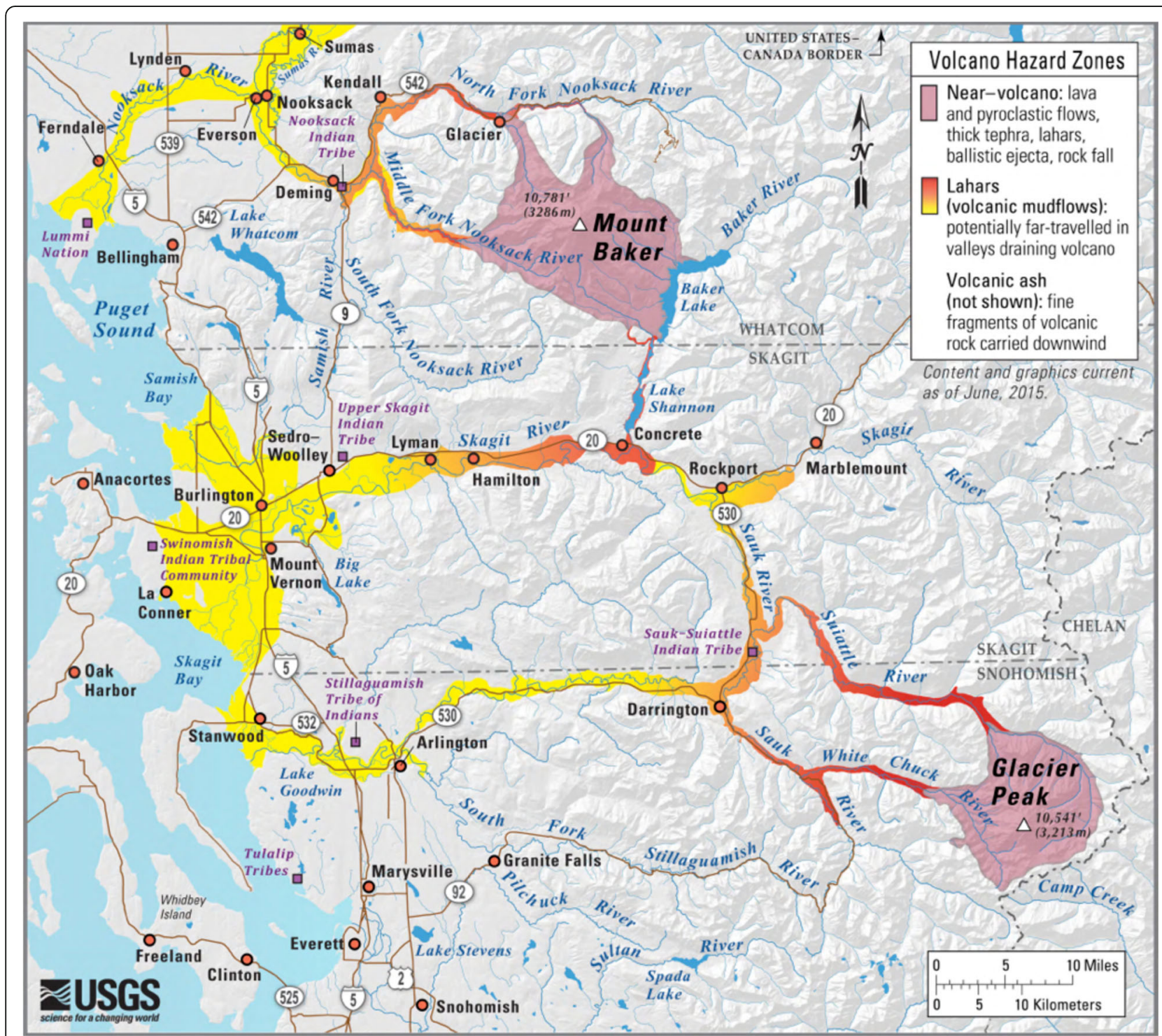

Fig. 1 Volcanic hazard map for Mount Baker and Glacier Peak showing lahar paths along Skagit River (U.S. Geological Survey, 2014) 
geographic information systems (GIS) reveals that nearly 40,000 lives and 15,000 homes are at risk in these lahar zones (Corwin 2016). If the entire lahar zone were inundated, hundreds of square kilometers of agricultural land could be rendered useless. Monetary losses from property alone could escalate to over $\$ 5$ billion based on the value of individual parcels (Skagit County Digital Data Warehouse 2014; Corwin 2016). Along with immediate financial impacts, the subsequent loss of nearly $\$ 62$ million dollars in tax revenue to the county could present further challenges for a recovering community. Major transportation routes, such as Interstate 5 (north-south) and the North Cascades Highway (east-west), intersect the lahar zone and damage to these networks could negatively impact response capacity. This potential for loss and the prospect of improving hazard management and community preparedness represent the primary motivation behind this study.

\section{Methods}

To address these research questions, an online survey questionnaire was administered to individuals living or working in the Skagit Valley. The questionnaire assessed their hazard knowledge, risk perception, and preparedness behaviors, particularly in relation to perceived response-efficacy, protective response cost, self-efficacy, and ascription of responsibility variables (Corwin 2016). Hazard knowledge was assessed by asking respondents to correctly identify which hazards affect the Skagit Valley and how the threat changes with distance from the volcano based on the official Mount Baker and Glacier Peak hazard maps (Fig. 1). Ascription of responsibility was examined by asking respondents to rate the level of responsibility they ascribe to various stakeholders (e.g., self, friends and family, local emergency services, neighbors or community members, FEMA) for their personal protection and provision of resources. Perceived self-efficacy was explored based on the respondent's level of agreement with statements indicating confidence in their knowledge, skills, and ability to prepare for, respond to, and recover from lahars and floods. To examine the importance of potential barriers to preparedness behaviors, respondents rated the influence of different variables (e.g., cost, time, hazard and preparedness knowledge, low response-efficacy beliefs, and reliance on community members and emergency services for support) on preparedness decisions.

The wording, order, and presentation of items in the questionnaire were developed with input and review from scientists at the Cascade Volcano Observatory (United States Geological Survey) and GNS Science (New Zealand's Geological Survey) as well as emergency management officials with the Washington State
Emergency Management Division and Skagit County Department of Emergency Management. The questionnaire incorporates questions modified primarily from the surveys of Davis et al. (2006), Barberi et al. (2008), and Johnston et al. (2012).

Survey participation was anonymous and voluntary, and respondents were recruited using a non-random convenience sampling method. The questionnaire was advertised through postcards distributed at local events, businesses, government offices, and libraries; phone calls and emails to local hospitals, first responder agencies, churches, schools, government offices, businesses, and social organizations; a newspaper article; and posts on local social media boards. Between August and December 2014, 507 individuals participated in the survey (See Table 1 for demographic data).

At the time of this study, the Skagit Valley lacked the extensive lahar readiness messaging found in communities within Mount Rainier's lahar zones. Unlike Mount Rainier, the drainages on Mount Baker and Glacier Peak were not instrumented with lahar monitoring devices, nor were there volcanic hazard sirens or evacuation signs posted. Information on volcanic hazards and how to prepare was available in the Emergency Resource Guide (Washington Military Department, Washington State Department of Health 2008) on the Skagit Valley

Table 1 Survey Participant Demographics Compared to Skagit County Population

\begin{tabular}{lll}
\hline Demographic & $\begin{array}{l}\text { Survey } \\
\text { participants }\end{array}$ & $\begin{array}{l}\text { County } \\
\text { population* }\end{array}$ \\
\hline Sex: ${ }^{1} n=455$ & & \\
$\quad$ Female & $63 \%$ & $50.8 \%$ \\
$\quad$ Male & $36 \%$ & $49.6 \%$ \\
Transgender, Prefer not to say, Other & $1 \%$ & - \\
Age: $n=451$ & & \\
18 to 24 & $8 \%$ & $11 \%$ \\
25 to 34 & $18 \%$ & $16 \%$ \\
35 to 44 & $21 \%$ & $15 \%$ \\
45 to 54 & $20 \%$ & $17 \%$ \\
55 to 64 & $22 \%$ & $18 \%$ \\
$65+$ & $12 \%$ & $23 \%$ \\
Income: $n=435$ & & \\
Under $\$ 49,999$ & $38 \%$ & $45 \%$ \\
$\$ 50,000$ to $\$ 74,999$ & $26 \%$ & $20 \%$ \\
$\$ 75,000$ to $\$ 99,999$ & $18 \%$ & $13 \%$ \\
$\$ 100,000$ to $\$ 149,999$ & $14 \%$ & $14 \%$ \\
$\$ 150,000$ and above & $4 \%$ & $7 \%$ \\
\hline
\end{tabular}

* 2014 American Community Survey 5-year estimates

${ }^{1}$ Sex operationalized as gender within survey questionnaire 
Emergency Management website. Public outreach efforts were underway to increase awareness and preparedness, including registering residents for the AlertSense emergency notification system and promoting general preparedness at local event information booths. Much of the focus was directed toward increasing preparedness and awareness relative to flood and fire hazards since these are more common events in the Skagit Valley. Additionally, our survey was conducted 5 months after the nearby landslide in Oso, WA killed 43 people. The proximity of this event likely increased awareness of and interest in landslide and debris flow hazards.

\section{Measuring household preparedness}

Survey participants were shown a list of commonly recommended household preparedness measures and asked to indicate which of the six activities they had undertaken and which of the fourteen items they had prepared. These activities and items are consistent with those recommended in the widely used Kit-Plan-Inform messaging framework and can be divided into three categories: (1) gathering supplies, (2) making a plan, and (3) seeking information. National, local, and nongovernmental organizations promoting this framework include the Department of Homeland Security's Ready.gov, Washington State Emergency Management Division, Skagit County Department of Emergency Management, American Red Cross, and Cascade Volcano Observatory.

The checklist of preparedness measures on the questionnaire included fourteen supply items (e.g., food and water for 3 days, flashlight and radio with extra batteries, blankets), two planning activities (e.g., establishing a plan for contacting family members, designating an out-ofarea emergency contact), and four information seeking actions (e.g., seeking information on local volcanic hazards, learning first aid, learning who in the community may need additional help). These measures were grouped into a typology of hazard adjustments based on the Kit-Plan-Inform categories, which we refer to as the supplies, planning, and action indicators hereafter.

The number of activities and items participants checked off on the provided list was tallied to generate a raw score for each indicator. These raw scores were standardized to their corresponding $\mathrm{z}$-scores by subtracting the indicator's mean from each individual score and dividing by the indicator's standard deviation. The resulting scores exhibit a mean of zero and a standard deviation of one. Finally, the three standardized indicator scores were combined and averaged into an equally weighted linear composite score for preparedness (hereafter CP score). The average CP score is zero, positive scores indicate above average preparedness, and negative scores indicate below average preparedness.
Measuring preparedness with an equally weighted linear composite score rather than a raw count of activities and items substantially increases the importance of the planning and action indicators. Although these two indicators consist of far fewer measures than the supplies indicator, with the $\mathrm{CP}$ score, each indicator accounts for a third of the participant's total preparedness. We assume that planning and information seeking actions are equally as important as gathering supplies and designed the $\mathrm{CP}$ score to reflect this assumption. Overall, the CP score provides (1) a continuous variable for measuring household preparedness, (2) a means for comparing household preparedness across individuals and groups, and (3) a measure that places less emphasis on individual supplies and more on planning and information seeking actions.

\section{Data analysis}

A combination of data types were collected including nominal, ordinal, and continuous. We relied extensively on 5-point Likert-type questions that, with some variations, asked participants to rate their agreement with statements on a scale of 1 (strongly disagree) to 5 (strongly agree). Where necessary, an "I don't know" category was included.

Data analysis was conducted using $\mathrm{R}$ version 3.3.2 (R Core Team 2016) and standard statistical tests. To test for independence between two variables based on observed response frequencies, we use chi-square tests. For Likert-type responses, the 1 and 2 rankings as well as the 4 and 5 rankings were combined to ensure minimum expected values greater than five in chi-square tests. T-tests were used to test for differences between the means of two groups. The Spearman's rho $(\rho)$ correlation coefficient was used to measure association between two variables because at least one variable was ordinal in each comparison.

\section{Results}

\section{Barriers to preparedness behaviors}

We examine the role that perceived response-efficacy, self-efficacy, protective response costs, and ascription of responsibility variables play in preventing preparedness actions by asking respondents to rate the extent to which they agree or disagree, on a 5-point Likert scale, with a series of suggested barriers (Table 2). None of the proposed barriers to preparedness actions garner a majority of support among respondents (Table 2). The four most frequently cited barriers-lack of hazard knowledge, lack of preparedness knowledge, cost, and time commitment-hinder preparedness for 23 to $35 \%$ of the survey population. These represent perceived protective response costs as well as actual resources people may lack. For the majority of respondents (77-62\%), however, 
Table 2 Response frequencies and ranking of suggested barriers to the adoption of further preparedness actions

\begin{tabular}{|c|c|c|c|}
\hline Suggested barrier & Agree $^{a}$ & Neutral & Disagree $^{b}$ \\
\hline $\begin{array}{l}\text { Not knowing what hazards could } \\
\text { affect me }\end{array}$ & $35 \%$ & $27 \%$ & $38 \%$ \\
\hline Not knowing what to prepare & $28 \%$ & $28 \%$ & $44 \%$ \\
\hline Cost (too expensive) & $26 \%$ & $37 \%$ & $37 \%$ \\
\hline Too time consuming & $23 \%$ & $41 \%$ & $36 \%$ \\
\hline $\begin{array}{l}\text { I don't think a natural hazard is likely } \\
\text { to affect me }\end{array}$ & $14 \%$ & $23 \%$ & $63 \%$ \\
\hline $\begin{array}{l}\text { Inaccurate, uncertain, or difficult to } \\
\text { understand science, information, or } \\
\text { maps }\end{array}$ & $13 \%$ & $40 \%$ & $47 \%$ \\
\hline Items will not help me protect myself & $7 \%$ & $22 \%$ & $71 \%$ \\
\hline $\begin{array}{l}\text { My neighbors/community members } \\
\text { have these items and will assist me }\end{array}$ & $6 \%$ & $26 \%$ & $68 \%$ \\
\hline $\begin{array}{l}\text { Emergency services provides necessary } \\
\text { items and assistance }\end{array}$ & $3 \%$ & $14 \%$ & $83 \%$ \\
\hline
\end{tabular}

Note: $\mathrm{n}$ varies from 459 to 463 due to missing values

${ }^{a}$ Responses of 4 or 5 on a 5 -point Likert scale

${ }^{\mathrm{b}}$ Responses of 1 or 2 on a 5-point Likert scale. Suggested barrier order

determined based the percentage of respondents selecting 4 or 5 (agree)

these four, frequently-cited barriers do not prevent further preparedness. The suggested barriers related to ascription of responsibility (reliance on emergency services and neighbors/community members for resources and assistance) and perceived response-efficacy ("Items will not help me protect myself") were rated as least important (Table 2). Less than ten percent of respondents consider these barriers to greater household preparedness.

In addition to asking respondents to rate the importance of suggested barriers, we compared measures of ascription of responsibility and perceived self-efficacy to preparedness scores. T-test results indicate that a difference exists between the preparedness levels of those who consider themselves "very responsible" for their safety and provision of resources and those who do not (Table 3). The former have an above average $\mathrm{CP}$ score while the latter have a below average $\mathrm{CP}$ score. We also find a weak but positive correlation between ascription of responsibility to self and preparedness (Table 4). Both results suggest that people who feel more personally responsible for their safety prepare more. Ascription of responsibility to local emergency services and FEMA, however, are both negatively associated with CP score (Table 4), suggesting preparedness decreases when the level of responsibility a respondent attributes to local and federal emergency services increases.

Ratings for all perceived self-efficacy statements correlate positively with $\mathrm{CP}$ scores (Table 4), meaning those who rate their knowledge, skills, and abilities higher also tend to be better prepared. This is true across all indicator variables. Additionally, correlations between preparedness and self-efficacy are stronger when the self-efficacy statement refers to preparedness for natural hazards in general (first statement in Table 4) rather than response and recovery activities for lahars specifically. In fact, the correlation between preparedness and the first selfefficacy statement represents the strongest correlation recorded in the present study. No significant difference is found between preparedness and perceived self-efficacy when considering a frequently occurring hazard (flooding) as opposed to a rarer hazard (lahars) given the overlap in the $95^{\text {th }}$ percentile confidence intervals.

\section{Professional participation's influence on household preparedness \& personal beliefs}

Previous studies indicate that increased public participation in hazard management should positively influence preparedness levels, knowledge, trust in officials, ascription of responsibility, and perceived self-efficacy (Paton et al. 2008; Wachinger et al. 2013). To test whether or not these specific advantages also apply in the case of professional participation in hazard management, we divide the survey participants into two populations, response professionals and laypeople, and compare their responses on these five topics. Response professionals are 73 individuals who self-identify as first responders or leaders in local city government, hospitals, school districts, Red Cross, or utilities, transportation, or water companies. These individuals participate in hazard management at a professional level. The term laypeople refers to the other 383 survey respondents from the public.

\section{Preparedness levels}

T-tests comparing the average preparedness scores (i.e., $\mathrm{CP}$, planning, supplies, and action scores) of response professionals and laypeople reveal a lack of statistically

Table 3 Average preparedness score of respondents by personal responsibility level

\begin{tabular}{|c|c|c|c|c|c|}
\hline \multirow[b]{2}{*}{ Independent variable } & \multirow[b]{2}{*}{ Respondents } & \multicolumn{4}{|c|}{ Dependent variable: CP score } \\
\hline & & Mean & Standard deviation & t-value & $p$-value \\
\hline $\begin{array}{l}\text { Respondent feels "very responsible" for their own protection } \\
\text { and provision of resources: }\end{array}$ & $n=456$ & & & $3.16(103)$ & 0.002 \\
\hline Yes & $83 \%$ & 0.06 & 0.75 & & \\
\hline $\mathrm{No}^{\mathrm{a}}$ & $17 \%$ & -0.26 & 0.80 & & \\
\hline
\end{tabular}

ancludes responses of 2, 3, and 4. None of the respondents selected 1, or "not responsible" 
Table 4 Spearman's Rho Correlations Among Composite Preparedness Scores and Ascription of Responsibility Beliefs/ Perceived Self-Efficacy Statements

\begin{tabular}{|c|c|c|}
\hline Statements & $\begin{array}{l}\text { CP } \\
\text { Score }\end{array}$ & $\mathrm{Cl}(95 \%)$ \\
\hline \multicolumn{3}{|c|}{$\begin{array}{l}\text { How responsible will each of the following entities be for your } \\
\text { protection and providing necessary resources? }{ }^{\mathrm{a}}(n=411)\end{array}$} \\
\hline Self & $0.19^{* * *}$ & $\begin{array}{l}{[0.10,} \\
0.28]\end{array}$ \\
\hline Friends \& Family & $0.13^{* *}$ & $\begin{array}{l}{[0.03,} \\
0.22]\end{array}$ \\
\hline Local Emergency Services & $-0.14^{* *}$ & $\begin{array}{l}{[-0.23,} \\
-0.04]\end{array}$ \\
\hline Community Members & 0.07 & $\begin{array}{l}{[-0.03,} \\
0.17]\end{array}$ \\
\hline FEMA & $-0.14^{* *}$ & $\begin{array}{l}{[-0.23} \\
-0.04]\end{array}$ \\
\hline
\end{tabular}

To what extent do you agree or disagree with the following statements? ${ }^{\mathrm{b}}(n=448)$

I have the knowledge and skills to ensure that I $\quad 0.43^{* * *}[0.35$, am prepared for a naturathazard:

I have the ability to protect myself and/or others $0.19^{* * *}[0.10$, from the effects of a lahar:

I have the ability to protect myself and/or others $\quad 0.26^{* * *}[0.17$ from the effects of a flood:

I am confident that I will know what to do during $0.25^{* * *}$ and after a lahar:

I am confident that I will know what to do during $\quad 0.31^{* * *} \quad[0.22$ and after a flood:

0.39]

${ }^{* *}$ Correlations significant at the $\mathrm{p}<0.01$ level. ${ }^{* * *}$ Correlations significant at the $\mathrm{p}<0.001$ level

${ }^{\text {a }}$ Responses rated on a five-point scale with $1=$ not responsible and $5=$ very responsible

${ }^{\mathrm{b}}$ Responses rated on a five-point scale with $1=$ strongly disagree and $5=$ strongly agree

Table 5 Average Preparedness Scores of Response Professionals and Laypeople

\begin{tabular}{|c|c|c|c|c|}
\hline $\begin{array}{l}\text { Independent Variable } \\
(n=448)\end{array}$ & Mean & Standard deviation & t-value & $\mathrm{p}$ \\
\hline & \multicolumn{4}{|c|}{ Dependent Variable: Planning Score } \\
\hline Response Professional & 0.15 & 1.02 & $1.43(98)$ & 0.157 \\
\hline \multirow[t]{2}{*}{ Laypeople } & -0.03 & 0.99 & & \\
\hline & \multicolumn{4}{|c|}{ Dependent Variable: Supplies Score } \\
\hline Response Professional & 0.13 & 0.96 & $1.18(102)$ & 0.241 \\
\hline \multirow[t]{2}{*}{ Laypeople } & -0.01 & 0.99 & & \\
\hline & \multicolumn{4}{|c|}{ Dependent Variable: Action Score } \\
\hline Response Professional & 0.21 & 0.91 & $2.05(107)$ & 0.042 \\
\hline \multirow[t]{2}{*}{ Laypeople } & -0.03 & 1.00 & & \\
\hline & \multicolumn{4}{|c|}{ Dependent Variable: CP Score } \\
\hline Response Professional & 0.17 & 0.69 & $2.12(107)$ & 0.036 \\
\hline Laypeople & -0.03 & 0.76 & & \\
\hline
\end{tabular}

significant difference between the average planning and supplies indicator scores of these two groups (Table 5). However, the average action indicator score is significantly greater for response professionals, which results in an average $\mathrm{CP}$ score for response professionals that is higher than the score for laypeople. Overall, response professionals have an above average preparedness score while laypeople exhibit slightly below average preparedness.

Variations in household preparedness were examined in greater detail by comparing the number of specific recommended preparedness measures adopted by response professionals and laypeople (Table 6). A statistically significant difference in preparedness exists for five of the 20 preparedness measures listed, all of which correspond to an increase in preparedness among response professionals. Compared

Table 6 Preparation of individual recommended preparedness measures by response professionals and laypeople

\begin{tabular}{|c|c|c|}
\hline & $\begin{array}{l}\text { Response } \\
\text { professional }\end{array}$ & Laypeople \\
\hline \multicolumn{3}{|l|}{ Planning Indicator } \\
\hline Plan for contacting family members & $44 \%$ & $40 \%$ \\
\hline $\begin{array}{l}\text { Emergency contact person } \\
\text { outside the area* }\end{array}$ & $56 \%$ & $43 \%$ \\
\hline \multicolumn{3}{|l|}{ Supplies Indicator } \\
\hline Flashlight and extra batteries & $77 \%$ & $71 \%$ \\
\hline $\begin{array}{l}\text { Water: } 1 \text { gallon/person/day } \\
\text { for } 3 \text { days }\end{array}$ & $49 \%$ & $51 \%$ \\
\hline Non-perishable food for 3 days & $67 \%$ & $63 \%$ \\
\hline Non-electric can opener & $82 \%$ & $78 \%$ \\
\hline Portable radio and extra batteries & $48 \%$ & $48 \%$ \\
\hline Fire extinguisher & $68 \%$ & $69 \%$ \\
\hline Smoke detector* & $84 \%$ & $72 \%$ \\
\hline First aid kit & $89 \%$ & $81 \%$ \\
\hline Essential medicine & $47 \%$ & $49 \%$ \\
\hline Sturdy shoes & $74 \%$ & $64 \%$ \\
\hline Whistle & $42 \%$ & $42 \%$ \\
\hline Wrench or pliers to turn off utilities & $67 \%$ & $60 \%$ \\
\hline Local maps & $38 \%$ & $35 \%$ \\
\hline Blankets or sleeping bags & $84 \%$ & $74 \%$ \\
\hline \multicolumn{3}{|l|}{ Action Indicator } \\
\hline $\begin{array}{l}\text { Bought additional insurance } \\
\text { (e.g., home) }\end{array}$ & $16 \%$ & $23 \%$ \\
\hline $\begin{array}{l}\text { Sought out information on local } \\
\text { volcanic hazards*** }\end{array}$ & $44 \%$ & $23 \%$ \\
\hline $\begin{array}{l}\text { Someone in the family has learned } \\
\text { to provide first aid*** }\end{array}$ & $85 \%$ & $59 \%$ \\
\hline $\begin{array}{l}\text { Know who in your neighborhood } \\
\text { or community may need additional } \\
\text { help (e.g., elderly, families with small } \\
\text { children)*** }\end{array}$ & $62 \%$ & $35 \%$ \\
\hline
\end{tabular}

Note: $\mathrm{n}$ varies from 455 to 451 due to missing values. Chi-square test of association significant at the ${ }^{*} p<0.05$ level and ${ }^{* * *} p<0.001$ level 
to laypeople, more response professionals have someone in their family that has learned to provide first aid $(+26 \%)$, personally know who in their neighborhood or community may need additional assistance during a natural hazard $(+26 \%)$, and have sought out local volcanic hazard information $(+21 \%)$. Additionally, but to a lesser extent, more response professionals have identified a non-local emergency contact $(+13 \%)$ and installed a smoke detector $(+12 \%)$. This represents only a minimal improvement in preparedness levels among those participating in hazard response planning and implementation professionally.

\section{Knowledge}

A respondent's ability to correctly interpret local volcanic hazard maps was used as an indicator of hazard knowledge. Participants were provided the U.S. Geological Survey's Mount Baker volcanic hazard map and asked to identify which hazards would affect the Skagit Valley and whether the hazard increases, decreases, or remains the same with distance from the volcano. When interpreted correctly, respondents select that only lahars impact the Skagit Valley and the hazard decreases downstream, away from the volcano.

Nearly all respondents in both groups correctly identify that lahars affect the Skagit Valley, but many also select thick tephra, pyroclastic flows, lava, or rockfall hazards (Table 7). Overall, only $37 \%$ of response professionals and $45 \%$ of laypeople-a difference that is not statistically significant-answer this question correctly (i.e., only select lahars). On the second map interpretation question, nearly $60 \%$ of respondents in both groups correctly answer that

Table 7 Interpretation of the Mount Baker volcanic hazard map by response professionals and laypeople

\begin{tabular}{lll}
\hline \multicolumn{2}{c}{$\begin{array}{c}\text { Response } \\
\text { professional }\end{array}$} & Laypeople \\
\hline Which hazards impact the Skagit Valley? $(n=455)$ & $41 \%$ \\
Thick tephra* & $55 \%$ & $27 \%$ \\
Lava & $30 \%$ & $95 \%$ \\
Lahar $^{2}$ & $96 \%$ & $25 \%$ \\
Pyroclastic flow & \\
Rock Fall & $38 \%$ & $25 \%$
\end{tabular}

Does the hazard from Mount Baker increase, decrease, or remain the same with distance downstream? $(n=454)$

$\begin{array}{lll}\text { Increase } & 33 \% & 28 \% \\ \text { Decrease } & 58 \% & 60 \% \\ \text { Remain the same } & 10 \% & 12 \% \\ \text { Overall map interpretation } & & \\ \text { Correctly identify hazard } & 37 \% & 45 \% \\ \text { Correctly identify directionality of hazard } & 58 \% & 60 \% \\ \begin{array}{l}\text { Correctly interpret both hazard map } \\ \text { Questions }\end{array} & 27 \% & 29 \% \\ \end{array}$

* Response frequencies significantly different at the $p<0.05$ based on chi-square tests ${ }^{a} 1$ of 4 cells has minimum expected value less than 5 the lahar hazard decreases with distance downstream. Just over a quarter of response professionals and laypeople answer both questions correctly. Thus, response professionals fail to interpret local volcanic hazard maps more accurately than laypeople (Table 7), even though nearly twice as many response professionals have a history of seeking out local volcanic hazard information (Table 6).

\section{Confidence in officials}

Response professionals express greater confidence in officials' abilities to provide timely and effective instructions, response, and evacuation during a hazard than do laypeople (Fig. 2). Nearly half of response professionals are confident in the ability of officials to respond to a hazardous event successfully compared to only a quarter of laypeople. Additionally, less than a third of response professionals lack confidence in the abilities of officials compared to $44 \%$ of laypeople.

\section{Ascription of responsibility}

Statistically, both response professionals and laypeople assign responsibility for their personal safety and provision of resources in a similar manner (Fig. 3). Respondents in both groups state they, themselves, are most responsible for their personal safety during a natural hazard. They consider local emergency services as well as friends and family members the next most responsible followed by other community members and FEMA. Ascription of responsibility beliefs do not appear to change with increased professional participation.

\section{Perceived self-efficacy}

Significantly more response professionals agree with each self-efficacy statement than do laypeople (Fig. 4). This trend holds regardless of if the statement refers to a frequent hazard (flooding) or a rare hazard (lahars). However, the increase is more pronounced when considering flooding. On average, agreement with self-efficacy statements increases by $21 \%$ (range: $15-24 \%$ ) when respondents identify as response professionals.

Both response professionals and laypeople indicate lower levels of perceived self-efficacy when considering lahars as opposed to floods (Fig. 4). Among response professionals, agreement with the statement "I have the ability to protect myself and/or others" drops by $34 \%$ when framed in terms of a lahar instead of a flood. Among laypeople, this decrease is lower at $25 \%$ but still substantial. Participants' confidence that they will "know what to do during and after" a hazard decreases by approximately a third among both groups when considering a lahar instead of a flood.

\section{Discussion}

\section{Understanding preparedness behaviors in the context of previous models}

We find that protective response costs (e.g., knowledge, money, time) and perceived response-efficacy fail to 


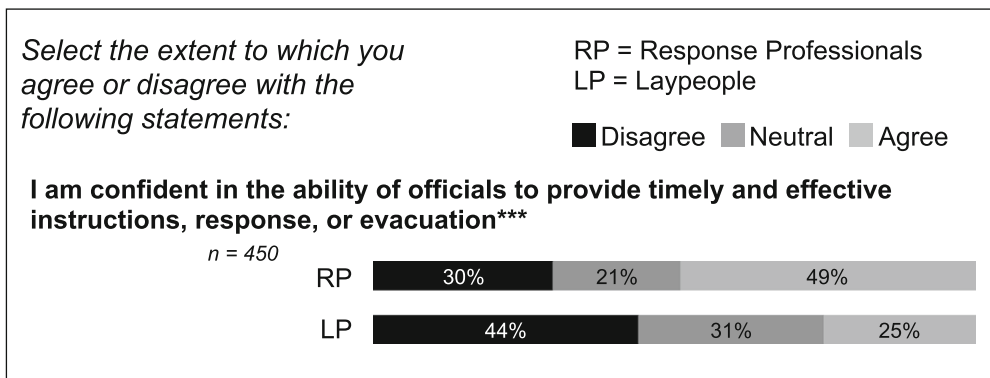

Fig. 2 Confidence in officials by response professionals and laypeople. Chi-square analysis indicates that response professionals are, to a statistically significant degree, more confident in the abilities of officials $\left({ }^{* * *} p<0.001\right)$

emerge as overwhelming barriers to preparedness behavior adoption. A third of respondents indicate that a lack of hazard knowledge prevents them from preparing and a quarter indicate that cost, time commitment, or a lack of preparedness knowledge influences their choices. Barely seven percent of respondents state that low responseefficacy beliefs ("items will not help me protect myself") prevent them from preparing further.

Perceived self-efficacy and ascription of responsibility are less readily recognized as barriers by respondents but significantly affect actual preparedness levels. The vast majority of respondents believe that a reliance on others for assistance does not reduce their preparedness behaviors (Table 2). Overall, $68 \%$ of respondents disagree with the idea that a reliance on their neighbors or other community members for supplies and assistance during a hazard event reduces their preparedness. Similarly, $83 \%$ feel that a reliance on emergency services for supplies and assistance does not hinder their own preparedness. Yet, correlations show a significant decrease in the adoption of preparedness actions among respondents who ascribe greater responsibility for their safety to others and a significant increase in preparedness among respondents who express high self-efficacy and personal responsibility (Tables 3 and 4).

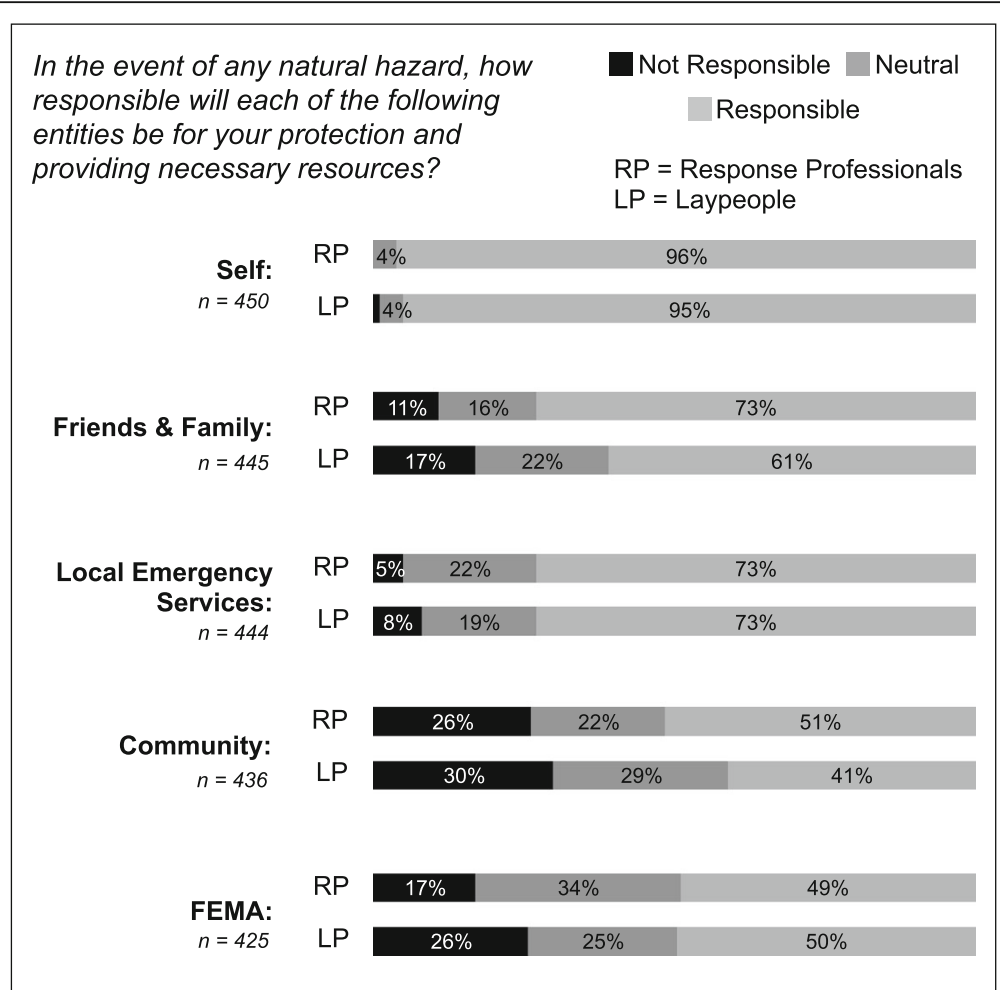

Fig. 3 Responsibility ascribed to various entities by response professionals and laypeople for safety and resources. Based on chi-square tests, no statistically significant difference exists between response professional and layperson ascription of responsibility. Both groups feel personally responsible for their safety and resource provision. Respondents view local emergency services as the next most responsible entity 


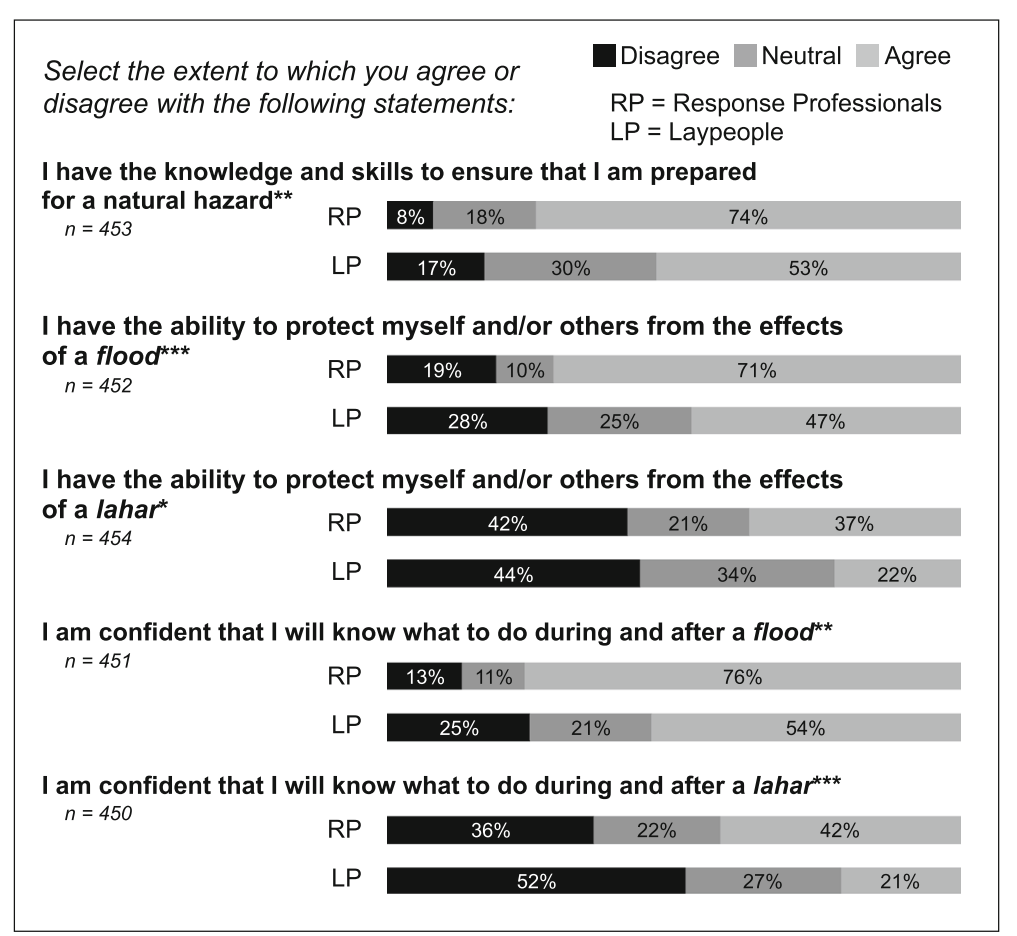

Fig. 4 Self-efficacy ratings by response professionals and laypeople. Response frequencies are significantly different at the levels ${ }^{*} p<0.05$, ${ }^{* *} p<0.01$, and ${ }^{* *} p<0.001$ (chi-square tests). Response professionals express greater perceived self-efficacy than laypeople

The following discussion opens by describing our findings regarding perceived response-efficacy and protective response costs in the context of previous studies. Although perceived response-efficacy and protective response costs are components of both PMT and PADM, PADM measures perceived response-efficacy in three ways-efficacy for protecting persons, efficacy for protecting property, and utility for other purposes. We specifically consider response-efficacy in terms of efficacy for protecting persons in the present study. As such, perceived response-efficacy in the following discussion refers exclusively to efficacy for protecting persons. This section closes with a discussion of findings related to perceived self-efficacy and ascription of responsibility beliefs.

\section{Perceived response-efficacy and protective response costs}

Lindell and colleagues examine the adoption of hazard adjustments (i.e., preparedness behaviors) among people living at risk from seismic (Lindell and Whitney 2000; Lindell and Prater 2002) and flood hazards (Terpstra and Lindell 2012). Lindell and Whitney assess data from university students in Los Angeles, Lindell and Prater focus on residents of three cities in California and three in western Washington, and Terpstra and Lindell study residents of coastal and riverine floodplains in the Netherlands. All three studies ask respondents to rate the hazard- and response-related attributes for various hazard adjustments, and Terpstra and Lindell ask respondents to indicate which attributes are important in their decision-making.

These three studies (Lindell and Whitney 2000; Lindell and Prater 2002; Terpstra and Lindell 2012) find that perceived response-efficacy significantly and positively influences the adoption of preparedness intentions and behaviors. Additionally, Terpstra and Lindell find that $76 \%$ of respondents cite efficacy for protecting persons as the "most important" attribute they considered when making preparedness decisions. Given this link between high perceived response-efficacy, one might expect that the failure to adopt certain preparedness measures would stem from low perceived response-efficacy. However, when considering a list of recommended preparedness behaviors, we find that only $7 \%$ of Skagit Valley respondents believe the "items will not help me protect myself" and that this belief prevents them from preparing further. The vast majority (71\%) of respondents disagree with the idea that low perceived efficacy associated with these items prevents them from preparing. In other words, most respondents indicate that their reason for not adopting additional recommended preparedness behaviors does not stem from a belief that these behaviors will prove ineffective in the face of a natural hazard event.

Previous findings (Lindell and Whitney 2000; Lindell and Prater 2002; Terpstra and Lindell 2012) 
demonstrate that high perceived response-efficacy is helpful, perhaps necessary, for motivating the adoption of hazard adjustments. However, the present study's findings suggest that high response-efficacy alone may not be sufficient to motivate preparedness actions. To test this hypothesis, future studies should aim to better constrain the difference between individuals who (1) believe preparedness behaviors to be highly effective and choose to prepare and (2) believe the behaviors are effective but still fail to prepare. Such studies could help identify factors that moderate the influence of response-efficacy.

With regard to perceived protective response costs, our results align with those of Lindell and Whitney (2000), Lindell and Prater (2002), and Terpstra and Lindell (2012) where comparable concepts exist. We find that perceived protective response costs fail to affect preparedness behaviors for all but a small group of respondents. In the present study, around a quarter of respondents cite a lack of money $(26 \%)$, time $(23 \%)$, or preparedness knowledge (28\%) as barriers to preparedness. Terpstra and Lindell similarly find that few respondents consider cost (24\%), time and effort (34\%), and knowledge and skills (36\%) important when making preparedness decisions. A lack of hazard knowledge also emerges as barrier in the present study for $35 \%$ of respondents, but this concept does not correspond to any resource-related attributes in PADM. For some, an actual or perceived lack of resources influences their preparedness decisions, but to say that perceptions of protective response costs drive preparedness behaviors would be an overstatement.

Treating money, time, and knowledge as necessary resources for adopting preparedness actions raises the question of whether these function as perceived or actual barriers. Paton (2003), in the development of his social-cognitive preparation model (later renamed Critical Awareness Model), notes a distinction between intention and action. Paton describes how an individual's intention to prepare is mediated by factors such as a lack of resources. Grothmann and Reusswig (2006) likewise point to PMT's ability to distinguish between perceived and actual barriers. The former operate in the coping appraisal process and prevent the formulation of an intention to prepare, whereas the latter work on protection motivation, stopping the translation of these intentions into actions. Herein, we do not distinguish between the two because we do not differentiate between barriers in the intention formulation and behavior initiation phases.

The importance of distinguishing between actual and perceived barriers is evident when considering monetary barriers. For respondents from higher income brackets, the monetary expense associated with preparing may represent a perceived protective response cost rather than an actual lack of resources. These individuals may believe that the costs outweigh the potential benefits of preparing. In contrast, others may understand the benefits of preparing and desire to adopt preparedness measures but lack the necessary resources to do so. In this case, cost becomes an actual barrier. Yet, regardless of the distinction between perceived and actual costs, our results and those of Terpstra and Lindell (2012) indicate that perceived costs do not pose a barrier for the majority of respondents.

Another potentially important difference between our study and those of Lindell and colleagues (Lindell and Whitney 2000; Lindell and Prater 2002; Terpstra and Lindell 2012), which is applicable to the discussion of both perceived response-efficacy and protective response costs, deals with the operationalization of attribute and barrier ratings. The present study asks respondents to rate the extent to which various factors (i.e., barriers) prevent them from preparing items on a commonly recommended checklist of emergency supply items, emergency planning activities, and information seeking activities. Lindell and Whitney, Lindell and Prater, and Terpstra and Lindell ask this question in greater detail: the first two studies ask respondents to rate the hazard- and resource-related attributes associated with individual adjustments and the third study requests these ratings for adjustments grouped based on their purpose (e.g., emergency kits, hazard information, emergency plans). Our study presents results based on a still coarser grouping of preparedness measures. This raises questions as to how variations in the number of items under consideration could affect respondents' ratings of perceived response-efficacy and protective response costs.

\section{Perceived self-efficacy}

Our finding that perceived self-efficacy positively motivates preparedness behaviors agrees with the longstanding and extensive research into self-efficacy's influence on intention and behavior motivation (Bandura 1997 and references therein). Evidence supporting selfefficacy's role in behavior motivation has led to the inclusion of self-efficacy and related concepts as variables in numerous behavior motivation theories, including the Social Cognitive Theory (Bandura 1997), Theory of Planned Behavior (TPB; Ajzen 1991), Critical Awareness Theory (Paton 2003; Paton et al. 2005), and PMT (Maddux and Rogers 1983). Meta-analytic studies evaluating TPB (Godin and Kok 1996; Armitage and Conner 2001) and PMT (Floyd et al. 2000) highlight the broad support for perceived self-efficacy as a predictor of behavior. Thus, our findings further reinforce the need to include perceived self-efficacy measures in PMT, other behavior motivation theories, and future preparedness motivation studies. 


\section{Ascription of responsibility}

Our findings demonstrate the importance of including ascription of responsibility measures when evaluating preparedness intentions and behaviors. Results indicate that ascription of responsibility to self correlates with higher preparedness levels, whereas ascription of responsibility to others correlates with lower preparedness levels. Our findings agree with those of previous studies related to the adoption of seismic hazard adjustments (Lindell and Whitney 2000; Lindell and Perry 2000; Arlikatti et al. 2007). These studies find significant positive correlations between feelings of personal responsibility and preparedness behaviors among university students in Los Angeles (Lindell and Whitney 2000) and California and Washington residents (Arlikatti et al. 2007).

The results of the present study support the argument that, after becoming aware of a hazard's consequences, a feeling of responsibility for preventing said consequences is necessary to motivate an individual to act (Stern et al. 1999; Stern 2000; Slimak and Dietz 2006). These results agree with Paton (2003) and Wachinger et al.'s (2013) argument: when individuals transfer responsibility for their safety to others, preparedness suffers. In such cases, individuals fail to recognize their personal agency in the preparedness and response process. Wachinger et al. attribute such shifts to excessive trust in officials and the mistaken exaggeration of their abilities.

VBN theory's ascription of responsibility represents an important variable not fully accounted for within PMT's current structure. Perceived self-efficacy represents the component of PMT that most closely resembles the ascription of responsibility variable; however, the two concepts are distinct. Self-efficacy deals specifically with the question of, "am I able to respond effectively?" whereas ascription of responsibility asks, "am I responsible for responding?" The failure of respondents to recognize the significance of this variable (Table 2) serves to highlight the need for incorporating ascription of responsibility measures into protective behavior motivation studies. This is further reinforced by Lindell and Perry's (2012) inclusion of protective responsibility perceptions within the social stakeholder perceptions component of PADM in a recent modification of the model.

\section{Professional participation's influence on household preparedness \& personal beliefs}

Professional participation appears to improve information seeking habits, confidence in officials, and selfefficacy. Yet, response professionals largely mirror laypeople in terms of their household preparedness levels, ascription of responsibility beliefs, and ability to read and interpret hazard maps. These results indicate that differences exist in how public and professional participation affect an individual's preparedness behaviors and personal beliefs. This raises the question: why do both types of participation positively affect information seeking behavior, confidence in officials, and self-efficacy, while only public participation positively influences household preparedness, knowledge, and ascription of responsibility?

Self-efficacy and confidence in officials appear to improve regardless of the type of participation (e.g., public or professional) in which an individual engages. Wachinger et al. (2013) posit that an individual's self-efficacy and confidence in officials improve as they interact more with emergency officials. Both public and professional participation facilitates such interaction. The former increases interactions between the public and officials, while the latter increases interactions among officials. Additionally, it seems logical that response professionals foster higher self-efficacy-the belief in their ability to prepare and respond to hazards effectively-since they elected to pursue careers where their abilities are constantly tested.

Regarding ascription of responsibility, Wachinger et al. (2013) highlight the role that participation in hazard management could play in helping people take greater responsibility for their own safety. Wachinger et al. note that interactions with officials help the public gain a more realistic understanding of their own abilities and the abilities of officials. Members of the public become better acquainted with the measures they can take to prepare, as well as what officials will expect them to bear personal responsibility for during an event. Similarly, Paton et al. (2008) emphasize the need for officials to "empower" the public to take personal responsibility for their safety. Given this emphasis on public participation's positive influence on personal responsibility, the similarity between the ascription of responsibility beliefs of response professionals and laypeople in our study seems to contradict expectations. However, it is important to note that laypeople in the Skagit Valley already feel primarily responsible for their own safety. With 95\% of laypeople already claiming that they are responsible for their own safety, there is not much room for improvement among the response professional community.

In terms of household preparedness, response professionals appear better prepared than laypeople based on their average $\mathrm{CP}$ score, but a closer analysis of indicator scores reveals that response professionals are only significantly more prepared in the action indicator category. This difference results because more response professionals have someone in their family who knows first aid and are aware of vulnerable people living in their community. Both of these recommended preparedness actions are strongly tied to professional responsibilities, 
particularly for first responders and hospital administrators. Thus, it may be more reasonable to attribute increases in these two measures to occupational requirements rather than voluntary preparedness behaviors induced by participation in response planning. All other variations in preparedness of individual measures are minor or not significant. This fact is emphasized by the lack of statistically significant differences in the average planning and supplies indicator scores.

The lack of improvement in household preparedness among response professional respondents may originate because public and professional participation in hazard management represent fundamentally different types of participation. While both aim to improve overall community preparedness and hazard response capabilities, each takes a different approach with separate objectives. Public participation programs tend to be geared toward improving household preparedness or ensuring that hazard plans align with community values. In contrast, trainings for response professionals might only discuss household preparedness as a minor component of a program largely focused on occupational responsibilities for whole community preparedness and response.

For example, one way the public participates in hazard management in the Skagit Valley is through the Community Emergency Response Team (CERT). CERT training teaches individuals about relevant local hazards, preparedness options, and basic disaster response skills (e.g., fire safety, light search and rescue, team organization, and disaster medical operations; Federal Emergency Management Agency 2016). Participating individuals are encouraged to get involved in community preparedness projects. Professional participation activities, on the other hand, focus more on developing an individual's professional competencies-knowledge and skills that allow their organization to respond effectively within the broader emergency management framework. Household preparedness may increase among the public because participation programs specifically and strongly emphasize how an individual can protect their home and family.

Although response professionals may be acquainted with recommended household preparedness measures, they may still fail to adopt these measures at home. For many response professionals, household preparedness measures do not directly benefit them because they are actively responding to a hazard. However, preparedness measures can help their families, and public health professionals admit that one of their primary concerns during a hazard event is the protection of their family (Slepski 2007). Such concerns can cause distraction or even prevent response professionals from reporting for work (Blessman et al. 2007). Thus, rather than focusing training programs on what to prepare and why, training should focus on how household preparedness can specifically benefit response professionals. Training programs should take a 'whole community' approach-emphasizing how household preparedness protects family members, helps response professionals better perform their job duties, and strengthens the whole community. Additionally, we agree with Blessman et al. (2007) recommendation to focus on providing response professionals with small, easily accomplishable steps.

The fact that response professionals and laypeople foster similar household preparedness levels has implications for previous studies of response professionals. The low levels of preparedness previously found among public health employees (Blessman et al. 2007; Rebmann et al. 2013) and first responders (Federal Emergency Management Agency 2016) may be indicative of low levels of preparedness among the public in general. A more representative survey examining a random sample of response professionals and the general public would be necessary to confirm this argument.

Additionally, questions remain regarding the generalizability of these findings, especially given the discrepancy between the expected and demonstrated influence of professional participation on household preparedness. We combined a variety of professions into the group "response professionals," but the type of participation performed by a first responder may differ substantially from that of a utilities, school, or hospital administrator. By more narrowly defining the "response professionals" category, future studies could determine how well these findings characterize response professionals in general versus subgroups based on specific characteristics of participation (e.g., occupation type, length of involvement, or types of trainings attended). We also lack demographic data on response professionals in the Skagit Valley with which to compare the demographics of survey participants. However, given the tendency to sample more engaged participants with convenience samples, we might expect responses from response professionals to actually overestimate the effects of participation on preparedness.

\section{Advantages and disadvantages of survey methodology}

Several limitations stem from the sampling method employed. First, a convenience sample lacks randomness; thus, selection bias may affect the sample, reducing the generalizability of the results. Since a response rate cannot be determined with this method, we cannot account for an individual's inherent interest or willingness to participate. Second, the questionnaire was only available in English, which limited the participation of non-native English speakers, particularly among the Spanish-speaking population. In Skagit County, $5.1 \%$ of the adult (18+) population 
speaks Spanish or Spanish Creole at home (U. S. Census Bureau 2015). Thus, the survey responses likely underrepresent the views of Spanish-speaking residents. Third, using an online platform limited the number of responses from those without access to a computer or sufficient computer literacy to navigate the questionnaire. The accessibility of the survey tool limited responses from the elderly and those from lower socio-economic backgrounds.

The influence of socio-economic status on response rate is of particular concern in the Skagit Valley, especially among the smaller upstream communities that are most at-risk from lahars. Except Lyman, all of the towns we examine are characterized by lower median household incomes and higher percentages of people living below the poverty level than Washington in general (U.S. Census Bureau 2015). Washington's median household income is $\$ 60,294$, but in La Conner, Mount Vernon, Burlington, Sedro-Woolley, Hamilton, and Concrete, median household incomes ranges from $\$ 33,977$ to $\$ 48,399$. The percentage of people 18 or older living below the poverty level in Washington is $12.2 \%$ but ranges from $14.7 \%$ to $33.8 \%$ in these six towns. Concrete and Hamilton are closest to the volcanoes and the most threatened by lahars. In these two towns, $28.2 \%$ and $33.8 \%$ of adult residents live below the poverty level, respectively. The unique socio-economic status of Skagit Valley residents presents difficulties for conducting an online survey given the possibility of reduced computer access in lower income households. Respondent demographics (Table 1) also confirm reduced response rates $(-7 \%)$ among people with household incomes below $\$ 50,000$. Such biases could be avoided in the future by using or offering an option for requesting a physical questionnaire.

Although limitations exist, using an online questionnaire with a convenience sampling survey design provided an inexpensive, straight-forward, and relatively rapid means of collecting responses. This method was consistent with previous risk perception and preparedness studies (e.g., Siegrist and Cvetkovich 2000; Bird et al. 2010). While nonrandom sampling limits the ability to extrapolate trends to the broader population, such surveys still provide valuable information on perception and preparedness among the surveyed population. Identified trends demonstrate risk perception and preparedness levels among a portion of the community and may be indicative of broader trends that a future randomized sample survey could investigate.

\section{Additional theoretical and practical implications}

From this work, a number of additional theoretical implications arise for future research into preparedness barriers and the benefits of hazard management participation. Our use of respondent opinions in evaluating preparedness barriers reveals the need to refine these questions in terms of framing and format. When asking respondents to indicate the degree to which different factors prevented them from preparing, we framed each option as a potential barrier. In contrast, Terpstra and Lindell (2012) asked respondents which factors were most important in their preparedness decision-making. Their framing did not assume these factors were barriers or promoters of preparedness, but simply factors influencing decisions.

In terms of format, our study expanded upon Terpstra and Lindell's (2012) use of a dichotomous variable to assess importance. We allowed respondents to express a range of support for different barriers using an ordinal scale. Based on these ratings, we were able to construct a relative ranking of barrier importance. In addition to using an ordinal design, we recommend that future studies allow respondents to rank the relative importance of each barrier or hazard adjustment attribute to provide even greater insight into respondents' thoughts.

This research highlights the need for incorporating independent or indirect measures of barrier variables for comparison with preparedness behaviors. By including additional questions assessing perceived self-efficacy and ascription of responsibility, we were able to note contradictions between correlations and expressed opinions. Lindell and Whitney (2000), Lindell and Prater (2002), and Terpstra and Lindell (2012) also apply indirect measures of the importance of hazard adjustment attributes. They calculate correlations of attribute ratings for different adjustments with adoption intention and actual adoption. Future studies should similarly allow respondents to express their opinions regarding what motivates their preparedness choices and include corresponding independent measures to compare with preparedness levels. Including both measures provides insight into respondents' perceptions of barriers as well as actual correlations with behavior.

In terms of knowledge assessment, a third of the respondents who are aware that volcanic hazards exist in the Skagit Valley still indicate that a lack of hazard knowledge prevents them from preparing. This highlights the need to identify what specific knowledge respondents feel they are missing. A general awareness that volcanic hazards exist may feel insufficient. Respondents need to understand what a hazardous event will mean for them personally because understanding the personal impacts of a hazard influences preparedness motivation (Lindell and Perry 2012). People also need to know where to access hazard information. Nearly $23 \%$ of the survey population found that current information was difficult to find or understand and 29\% felt information was easy to find but unclear. Paton et al. (2008) 
emphasize that providing information consistent with population needs, values, and beliefs helps emergency managers strengthen trust, reduce uncertainty, and improve the acceptance of information. By determining what specific information the public lacks and desires, as well as how best to present this information, emergency managers can better tailor educational efforts to ensure that the messages and information disseminated are appropriate for their community.

Finally, our results underscore the need for more detailed studies of hazard knowledge, risk perception, and preparedness among the response professional community. Studying response professionals is important because they play a significant role in the success of hazard response efforts and can act as role-models for the broader community. Training programs often introduce response professionals to the concept of household preparedness, yet to date, the household preparedness behaviors and personal beliefs of response professionals remain largely unstudied. Increased program evaluation would provide a clearer understanding of whether or not professional training translates into household readiness. Additionally, comparative studies of response professionals and the general public could offer a means of measuring the success of training programs and provide a more extensive understanding of whole community preparedness.

Furthermore, analyses based on occupation could identify different types of professional participation and how each influences household preparedness and personal beliefs. Such studies could isolate elements shared between the most effective training programs within and across professional boundaries. The goal of these efforts being to increase household preparedness and reduce possible distractions facing response professionals. If response professionals feel confident in the safety of their families, they can feel comfortable responding, which ultimately benefits the whole community. Overall, the results presented here reveal the important role that participation type plays in determining household preparedness actions.

In terms of practical implications, the findings presented herein will be provided to local and state emergency managers to assist in the development of improved public education programs, professional training programs, and response plans. We support the recommendation of Paton et al. (2008) that emergency managers should strive to empower the public. Managers should help individuals recognize their own agency during hazard events and improve their self-efficacy, both of which clearly and positively influence preparedness behaviors. Hazard management participation efforts should also be expanded given the positive impact that participation appears to have on self-efficacy and feelings of responsibility, impacts which do not appear to be tied to specific types of participation. For response professionals, household preparedness measures should be presented as small, easily achievable steps that will benefit their family and help them better perform their response duties. Further research could also explore the opportunities that enhanced school-based hazard education and its links to community-based public education offer as a way to increase community empowerment and participation in preparedness activities (Johnson et al. 2016; Ronan et al. 2016).

This research will be shared with the Cascade Volcano Observatory $(\mathrm{CVO})$ as well. The CVO's input in the design of the survey questionnaire ensured the collection of information relevant to their design of volcanic hazard maps. The current hazard maps successfully communicate the main details of the hazard, but more nuanced elements are not as easily conveyed.

\section{Conclusions}

The findings presented here support the role of perceived self-efficacy and ascription of responsibility beliefs as drivers of preparedness actions. These findings demonstrate the value of including VBN theory's ascription of responsibility concept in examinations of preparedness behaviors and support Lindell and Perry's (2012) inclusion of protective responsibility in their recent modification of PADM. Including ascription of responsibility measures in future studies of PMT's coping appraisal could help better explain preparedness, but a regression analysis should be used to account for interaction effects. Protective response costs and low perceived response-efficacy failed to emerge as strongly influential barriers to preparedness. Questions remain as to how other variables may moderate perceived responseefficacy's importance in preparedness decisions.

Results from investigating the link between participation and preparedness in a professional context, indicate that an increase in self-efficacy, information seeking behavior, and trust in officials appear to occur regardless of the type of participation. The increase likely stems from the fact that any type of participation facilitates increased interactions with officials. Such interactions are often tied to the recognition of personal agency, strengthened trust in officials, and a more accurate understanding of the abilities of officials. In contrast, household preparedness appears to depend on factors unique to specific types of participation. This is perhaps due to different styles and objectives of training programs. Further analysis of household preparedness levels in comparison with occupation (e.g., first responder, administrator, emergency manager) and specific training programs could help identify traits that promote the adoption of household preparedness measures. 
Overall, survey respondents are moderately prepared for a lahar at a household level. On average, respondents previously prepared eight to nine of the recommended items. The five most commonly prepared items included a first aid kit (81\%), non-electric can opener (78\%), blanket or sleeping bag (75\%), smoke detector (74\%), and flashlight with extra batteries (71\%). At least half of respondents stated they had sufficient water (one gallon/ day/person) for 3 days and $63 \%$ had non-perishable food for 3 days. However, this does not indicate whether or not people have these items readily accessible. In terms of planning and information seeking activities, $40 \%$ of respondents have a plan for contacting family members, $46 \%$ have an out-of-area emergency contact identified, and $63 \%$ have someone in their family who knows first aid. Only a quarter of the population has previously sought out information about local volcanic hazards; however, over three-quarters are interested in learning more about local volcanic hazards. In anticipation of this interest, we provided survey respondents with links to educational materials on hazard preparedness at the end of the questionnaire.

These preparedness levels are largely consistent with those found in previous studies of seismic (Lindell and Whitney 2000), volcanic (Johnston et al. 2005), and general natural hazard (Johnston et al. 2012) preparedness in Washington. Lindell and Perry (2000) find that $75 \%$ of respondents have first aid kits, $46 \%$ have stored water, $72 \%$ have stored food, $35 \%$ have an earthquake plan, and $16 \%$ have sought earthquake information. In their study of high school and middle school students living in the Mt. Rainier lahar zone, Johnston et al. (2005) find high levels of preparedness of first aid kits (range: 82-68\%), smoke detectors (range: 97-89\%), and flashlights with extra batteries (range: 92-77\%). They find moderate to low levels of respondents having someone in the family who knows first aid (range: 68-66\%), a family emergency plan (range: 34-23\%), and an out-of-area emergency contact (range: 46-32\%). Johnston et al. (2012) document adoption percentages akin to those from Johnston et al. (2005) and also indicate that just over half of their respondents have stored water and food.

These household preparedness measures are recommended in most hazard contexts but represent only one aspect of preparedness, particularly for lahars. The speed and rapid arrival times associated with lahars necessitate fast reaction times and prior preparedness among at-risk populations. For those living within the lahar zone, survival depends on immediate evacuation to high ground. Any supplies must be prepared in advance and easily transportable to prove effective. Knowing about lahar hazards, evacuation signals, and evacuation routes are the primary factors in successfully preparing for lahars; however, at the time of this study, evacuation sirens and routes were not available in the Skagit Valley. Lahars affect people in surrounding areas as well, preventing access to resources such as emergency response services, health care facilities, and grocery stores. People may also lose power or utility access. As such, adopting household preparedness behaviors would prove most beneficial to those in surrounding areas.

For future studies, it would be interesting to compare our sample group to a sample group obtained through a random sample technique (an option not available for the current study). Future studies would benefit from providing the questionnaire and recruitment materials in Spanish to better reach Spanishspeaking residents. Also, providing an option to receive a paper copy of the questionnaire would assist those without easy access to or familiarity with a computer. Finally, future studies would benefit from collecting more details regarding response professionals, such as which agency they work with, whether they are employees or volunteers, and what types of hazard management training they have received.

In conclusion, this study helps identify existing community preparedness levels, constrain the factors preventing the adoption of protective actions, and reveal the intricacies of proposed methods for motivating preparedness. Understanding each of these elements and sharing these findings with stakeholders in the hazard management process represent necessary steps in improving whole community preparedness. As such, the results of this study will be made available to local and state emergency management, the Cascade Volcano Observatory, and the general public. With the number of people living at-risk from lahars continuing to grow, creating a more robust knowledge-base focused on understanding preparedness motivation becomes essential for developing effective hazard mitigation, preparedness, response, and recovery plans.

\section{Abbreviations}

CP Score: Composite preparedness score; PMT: Protective motivation theory; VBN Theory: Values-Beliefs-Norms Theory; PADM : Protective Action Decision Model

\section{Acknowledgements}

The authors would like to thank the Skagit County and Washington State Emergency Management Divisions, especially John Schelling, and scientists at the Cascade Volcano Observatory for working with us to design a questionnaire that would provide the most useful information. Thanks to Dr. Jeffrey Johnson and Dr. Thomas Wuerzer (Boise State University) for asking hard questions and providing invaluable advice throughout this study and to Dr. Michael Lindell and an anonymous reviewer for their excellent critique and suggested revisions. Thanks also to Josh Hewitt (Colorado State University) for consulting on the design of our statistical analyses. Finally, thank you to all of the survey participants who made this research possible and to Boise State University's Department of Geosciences Burnham Grant for funding this study. 


\section{Funding}

This research was funded through the Boise State University Department of Geosciences Burnham Grant. The funding body played no role in the design of the study; collection, analysis, and interpretation of data; or in writing the manuscript. The purpose of this grant is solely to promote graduate student research in the geosciences.

\section{Availability of data and materials}

Additional data and materials, including the full questionnaire and response frequency data, are available in Corwin (2016).

\section{Authors' contributions}

$\mathrm{KC}$ and $\mathrm{BB}$ designed the survey with input from $\mathrm{MH}$ and $\mathrm{DJ}$. $\mathrm{KC}$ and $\mathrm{BB}$ recruited participants in the Skagit Valley for the survey. Data analysis was conducted by KC. The final manuscript was prepared by KC with substantia input from $\mathrm{BB}, \mathrm{MH}$, and $\mathrm{DJ}$. All authors read, reviewed, and approved the final manuscript.

\section{Competing interests}

The authors declare that they have no competing interests.

\section{Author details}

'Department of Geosciences, Boise State University, Boise, ID, USA. ${ }^{2}$ Department of Public Policy and Administration, Boise State University, Boise, ID, USA. ${ }^{3}$ GNS Science/Massey University, Palmerston North, New Zealand.

Received: 14 September 2016 Accepted: 17 January 2017

Published online: 01 February 2017

\section{References}

Ajzen I. The theory of planned behavior. Organ Behav Hum Dec. 1991;50: 179-211. doi:10.1016/0749-5978(91)90020-T

Arlikatti S, Lindell MK, Prater CS. Perceived stakeholder role relationships and adoption of seismic hazard adjustments. Inte J Mass Emerg Dis . 2007;25: 218-56.

Armitage CJ, Conner M. Efficacy of the Theory of Planned Behaviour: A meta-analytic review. Brit J Soc Psychol. 2001:40:471-99. doi:10.1348/ 014466601164939

Bandura A. Self-efficacy: The exercise of control. New York: W.H. Freeman and Company; 1997.

Barberi F, Davis MS, Isaia R, Nave R, Ricci T. Volcanic risk perception in the Vesuvius population. J Volcanol Geoth Res. 2008;172(3-4):244-58. doi:10.1016/j.jvolgeores.2007.12.011.

Beget JE. Postglacial volcanic deposits at Glacier Peak, Washington, and potential hazards from future eruptions. U.S. Geological Survey Open-File Report. 1982. p. 82-830.

Beget JE. Glacier Peak, Washington: A potentially hazardous cascade volcano. Environ Geol. 1983;5(2):83-92. doi:10.1007/BF02381101.

Bird DK, Gisladottir G, Dominey-Howes D. Volcanic risk and tourism in southern Iceland: Implications for hazard, risk and emergency response education and training. J Volcanol Geoth Res. 2010;189(1-2):33-48. doi:10.1016/j.jvolgeores. 2009.09.020.

Blessman J, Skupski J, Jamil M, Jamil H, Bassett D, Wabeke R, Arnetz B. Barriers to at-home-preparedness in public health employees: Implications for disaster preparedness training. J Occup Environ Med. 2007;49(3):318-26. doi:10.1097/ JOM.0b013e31803225c7.

Core Team R. R: A language and environment for statistical computing. Vienna: R Foundation for Statistical Computing; 2016. http://www.R-project.org/.

Corwin KA. Living in lahar zones: Assessing hazard exposure, risk perception, and preparedness behaviors in communities within the Mount Baker and Glacier Peak volcanic hazard zones. Master's Thesis, Boise State University. 2016.

Davis M, Johnston D, Becker J, Leonard G, Coomer M, Gregg C. Risk perceptions and preparedness: Mt Rainier 2006 community assessment tabulated results. GNS Science Report. 2006.

Diefenbach AK, Wood NJ, Ewert JW. Variations in community exposure to lahar hazards from multiple volcanoes in Washington State (USA). J Appl Volcanol. 2015;4:4. doi:10.1186/s13617-015-0024-z.

Dragovich JD, McKay DTJ. Holocene Glacier Peak lahar deposits in the lower Skagit River Valley, Washington. Wash Geol. 2000;28(1/2):19-21.
Federal Emergency Management Agency. Community Emergency Response Teams. 2016. http://www.fema.gov/community-emergency-responseteams.

Federal Emergency Management Agency (n.d.) Ready Responder: Emergency planning for first responders and their families. https://www.ready.gov/sites/ default/files/documents/files/RRToolkit.pdf.

Floyd DL, Prentice-Dunn S, Rogers RW. A Meta-analysis of research on protection motivation theory. J Appl Soc Psychol. 2000;30(2):407-29. doi:10.1111/j.15591816.2000.tb02323.x.

Gardner CA, Scott KM, Miller CD, Myers B, Hildreth W, Pringle PT. Potential Volcanic Hazards from Future Activity of Mount Baker. Washington: Geological Survey Open File Report; 1995. p. 95-498.

Godin G, Kok G. The theory of planned behavior: A review of its applications to health- related behaviors. Am J Health Promot. 1996;11(2):87-98. doi:10.4278/ 0890-1171-11.2.87.

Grothmann T, Reusswig F. People at Risk of Flooding: Why Some Residents Take Precautionary Action While Others Do Not. Nat Hazards. 2006;38(1-2):101-20. doi:10.1007/s11069-005-8604-6.

Houts PS, Lindell MK, Hu TW, Cleary PD, Tokuhata G, Flynn CB. The protective action decision model applied to evacuation during the Three Mile Island crisis. Inter J Mass Emerg Dis. 1984;2:27-39.

Hyde JH, Crandell DR. Postglacial volcanic deposits at Mount Baker, Washington, and potential hazards from future eruptions. Geological Survey Professional Paper. 1978. p. 1022-C.

Johnson VA, Ronan KR, Johnston DM, Peace R. Improving the Impact and Implementation of Disaster Education: Programs for Children Through Theory-Based Evaluation. Risk Anal. 2016;36:2120-35. doi:10.1111/risa.12545.

Johnston D, Ronan K, Becker J, Gregg C, Davis M. Children's risk perceptions and preparedness: Mt Rainier 2005 hazard education assessment tabulated results. GNS Science Report, 2005/029. 2005.

Johnston DM, Orchiston C, Becker JS. Eastern Washington resident perceptions of natural hazard risks. GNS Science Report. 2012

Kovanen DJ, Easterbrook DJ, Thomas PA. Holocene eruptive history of Mount Baker, Washington. Can J Earth Sci. 2001;38:1355-66. doi:10.1139/e01-025.

Lindell MK, Perry RW. Behavioral foundations of community emergency planning. Washington, DC: Hemisphere Press; 1992.

Lindell MK, Perry RW. Household adjustment to earthquake hazard: A review of research. Environ Behav. 2000:32:461-501.

Lindell MK, Perry RW. The protective action decision model: Theoretical modifications and additional evidence. Risk Anal. 2012;32(4):616-32.

Lindell MK, Prater CS. Risk area residents' perceptions and adoption of seismic hazard adjustments. J Appl Soc Psychol. 2002;32(11):2377-92.

Lindell MK, Whitney DJ. Correlates of household seismic hazard adjustment adoption. Risk Anal. 2000;20:13-25.

Maddux JE, Rogers RW. Protection motivation and self-efficacy: A revised theory of fear appeals and attitude change. J Exp Soc Psychol. 1983;19:469-79. doi:10.1016/0022-1031(83)90023-9.

Parker CL, Barnett DJ, Fews AL, Blodgett D, Links JM. The Road Map to Preparedness: A competency-based approach to all-hazards emergency readiness training for the public health workforce. Public Health Rep. 2005; 120(5):504-14.

Paton D. Disaster preparedness: a social-cognitive perspective. Disaster Prev Manag. 2003;12(3):210-6. doi:10.1108/09653560310480686.

Paton D, Smith L, Johnston D. When good intentions turn bad : promoting natural hazard preparedness. Aust J Emerg Manag. 2005:20(1):25-30.

Paton D, Smith L, Daly M, Johnston D. Risk perception and volcanic hazard mitigation: Individual and social perspectives. J Volcanol Geoth Res. 2008; 172(3-4):179-88. doi:10.1016/j.jvolgeores.2007.12.026.

Pierson TC, Scott KM. Downstream dilution of a lahar: Transition from debris flow to hyperconcentrated streamflow. Water Resour Res. 1985;21(10): $1511-24$.

Rebmann T, Strawn AM, Swick Z, Reddick D. Personal disaster and pandemic preparedness of U.S. human resource professionals. J Biosafety Health Edu. 2013;1(1):1-7. doi:10.4172/jbhe.1000102.

Rodolfo KS. The hazard from lahars and jökulhlaups. In: Sigurdssson H, Houghton B, McNutt S, Rymer H, Stix J (eds) Encyclopedia of volcanoes. San Diego: Academic Press; 2000. p. 973-995.

Rogers RW. Cognitive and physiological processes in fear appeals and attitude change: A revised theory of protection motivation. In: Cacioppo BL, Petty LL, editors. Social psychophysiology: A sourcebook. London: Guilford; 1983. p. 153-76. 
Rogers RW, Prentice-Dunn S. Protection motivation theory. In: Gochman DS, editor. Handbook of health behavior research I: Personal and social determinants. New York: Plenum; 1997. p. 113-32.

Ronan KR, Haynes K, Towers B, Alisic E, Ireland N, Amri A, Davie S, Petal M. Child-centred disaster risk reduction: Can disaster resilience programs reduce risk and increase the resilience of children and households? Aust J Emerg Manag. 2016;31(3):49-58.

Siegrist M, Cvetkovich G. Perception of Hazards: The Role of Social Trust and Knowledge. Risk Anal. 2000;20(5):713-20. doi:10.1111/0272-4332.205064.

Sims JH, Baumann DD. Educational programs and human response to natural hazards. Environ Behav. 1983;15(2):165-89.

Skagit County Digital Data Warehouse (2014). http://www.skagitcounty.net/ Departments/GIS/Digital/main.htm. Accessed 1 May 2014

Slepski LA. Emergency preparedness and professional competency among health care providers during Hurricanes Katrina and Rita: Pilot study results. Disaster Manag Response. 2007;5(4):99-110. doi:10.1016/j.dmr.2007.08.001.

Slimak MW, Dietz T. Personal Values, Beliefs, and Ecological Risk Perception. Risk Anal. 2006;26(6):1689-705. doi:10.1111/j.1539-6924.2006.00832.x.

Stern PC. Toward a coherent theory of environmentally significant behavior. J Soc Issues. 2000;56(3):407-24. doi:10.1111/0022-4537.00175.

Stern PC, Dietz T, Abel T, Guagnano GA, Kalof L. A value-belief-norm theory of support for social movements: The case of environmentalism. Hum Ecol Rev. 1999;6(2):81-97. doi:10.2307/2083693.

Terpstra T, Lindell MK. Citizens' perceptions of flood hazard adjustments: An application of the Protective Action Decision Model. Environ Behav. 2012:45(8):993-1018. doi:10.1177/0013916512452427.

U.S. Census Bureau. 2010-2014 American Community Survey 5-Year Estimates. 2015. http://www.census.gov/programs-surveys/acs/. Accessed 2 Mar 2016.

U.S. Geological Survey. Cascade volcanoes simplified hazard maps. 2014. https://volcanoes.usgs.gov/vsc/multimedia/cvo_hazards_maps_gallery.html.

Vallance JW. Lahars. In Sigurdssson H, Houghton B, McNutt S, Rymer H, Stix J (eds), Encyclopedia of volcanoes. San Diego: Academic Press; 2000. p. 601-616.

Volcano Hazards Program U.S. Geological Survey. Hazards: Lahars. 2016. http://volcanoes.usgs.gov/vhp/lahars.html.

Wachinger G, Renn O, Begg C, Kuhlicke C. The risk perception paradoximplications for governance and communication of natural hazards. Risk Anal. 2013;33(6):1049-65. doi:10.1111/j.1539-6924.2012.01942.x.

Waitt RB, Mastin LG, Beget JE. Volcanic-Hazard Zonation for Glacier Peak Volcano, Washington. U.S. Geological Survey Open File Report. 1995. p. 95-499.

Washington Military Department, Washington State Department of Health. Emergency resource guide: Information to help you plan and prepare. 2008. DOH Pub \#821-001. http://www.skagitcounty.net/EmergencyManagement/ Documents/2008Emergency_Resource_Guide.pdf. Accessed 2 Jan 2016.

\section{Submit your manuscript to a SpringerOpen ${ }^{\circ}$ journal and benefit from:}

- Convenient online submission

- Rigorous peer review

- Immediate publication on acceptance

- Open access: articles freely available online

- High visibility within the field

- Retaining the copyright to your article 